\title{
Can Web Crawlers Revolutionize Ecological Monitoring?
}

Victor Galaz (1*), Beatrice Crona (1,5), Tim Daw (3), Örjan Bodin (1,4), Magnus Nyström (1,2), Per Olsson (1)

1. Stockholm Resilience Centre, Stockholm University, SE 10961 Stockholm, Sweden. 2. Department of Systems Ecology, Stockholm University, SE 10961 Stockholm, Sweden. 3. School of Development Studies, University of East Anglia, Norwich NR4 7TJ, UK,. 4. Department of Government, Uppsala University, Box 256, 75105 Uppsala, Sweden. 5. The Centre for the Study of Institutional Diversity, Arizona State University, Tempe, AZ 85287, USA.

*To whom correspondence should be addressed. E-mail: victor.galaz@stockholmresilience.su.se

Despite recent advances, monitoring of the ecosystem services necessary for human well-being is limited by insufficient data, the complexity of social-ecological systems as well as poor integration between data on changes in ecosystems and linked human systems. However, information and communications technology are revolutionizing the generation of, and access to, information. The question is, can ecological monitoring tap into these increased flows of information by "mining" the Internet for early warnings of approaching abrupt ecological changes? Here we make an initial exploration of the possibilities of using web crawlers, and unofficial data as complements to conventional ecological monitoring, with a special emphasis on possibilities and limits to avoid "late warnings", i.e. when ecosystems have already shifted to less desired states. We use examples from coral-reef ecosystems to explore the untapped potential, but also limitations of using web-based information to monitor and forewarn of negative ecological shifts.

It is well-known that feedbacks and cross-scale interactions in interconnected biophysical and socioeconomic systems create opportunities for major surprises and non-linear response at various spatial scales (Schneider and Root 1995, Gordon et al. 2008). Ecological surprises are likely, in which ecosystem behavior differs qualitatively from a priori expectations (Gunderson 2003). Ecosystems support a number of vital ecosystem services (ES) such as water purification and food production, but rapid changes such as climate and global markets, present serious challenges to their future ability to provide these life supporting services (Millennium Ecosystem Assessment 2005). This situation is worsened by the fact that national and international responses to abrupt change are either insufficient or nonexistent. Examples include collapsing fisheries at national and global scales (Berkes et al. 2006); irreversible shifts in freshwater ecosystems, coral reefs and soil productivity (Scheffer et al. 2001); and numerous other examples of degrading ES (Millennium Ecosystem Assessment 2005). Restoration can be difficult since feedbacks in the system may make new, undesirable ecosystem states stable (Scheffer et al. 2001; Gordon et al. 2008). Avoiding crossing thresholds is therefore of prime interest for sustainable governance of ES.

Despite advances in monitoring technology (Clark et al. 2001), it is evident that existing information on changes in ecosystem services tends to be poor, and contains serious data gaps. In addition, existing monitoring systems are unable to capture the impacts of rapid demographic, economic and sociopolitical change resulting from economic development and 
increasing global flows of information, trade and technology (Berkes et al. 2006; Carpenter et al. 2006; Millennium Ecosystem Assessment 2005). The difficulties in quantifying social and ecological uncertainty, the lack of expert agreement on what indicators to monitor, poor existing data, and the costs associated in setting up long-term monitoring programs (Walters 2007), all pose serious challenges for society's capacity to steer away from, or prepare for, abrupt changes in ecosystems and losses of related ES. This is particularly true for countries that suffer from poor governance and weak environmental institutions (Danilsen et al. 2003; UNEP 2007).

\section{The Rise and Potential of Information and Communications Technology}

The importance of information and communication technology (ICT) for economic growth, education, and human development, has been widely discussed (Leach and Scoones 2006). Meanwhile, the evolution of "Web 2.0", with more interactive use of the Internet allows users to post, edit, comment on and provide information in blogs, wikis, podcasting, videoblogs, and other networking tools. Globally, access to information technology is very unequally distributed (IER 2005; Leach and Scoones 2006), but access to, and use of the Internet is rapidly increasing in all regions. For example, between 2000-2004, the number of Internet users in the developing world tripled from 96 to almost 333 million, while in Africa the number increased more than five-fold from 4.3 to 21.8 million (IER 2005:2).

The rapid evolution of ICT not only leads to increased flows of information at a global scale, but also sets the stage for innovative uses of "informal" data - ranging from e-mail lists, and local newspaper articles, to preprints of peer-reviewed journal articles - as an important complement to conventional ecological monitoring. The potential of ICT is currently being explored in a number of contexts for ecology, e.g. the resilience assessment wikipedia (1), online datasets such as those posted by the U.S. National Center for Ecology and Analysis and Synthesis (2), and uses of the Internet in citizen science projects (Levitt 2002). Crowl and colleagues (2008) in addition, suggest the creation of a coordinated "cyber-infrastructure" to facilitate prompt warnings of invasive alien species (IAS) and infectious diseases.

Here, we make a first elaboration of the possibilities and limitations of more systematic "data mining" of the Internet, and its potential to provide complementary information and "early warnings" about not only discrete ecological events (e.g. a disease outbreak caused by invasive species), but also information about changes in drivers as well as impacts of ecosystem change to forewarn of losses of ES.

1) http://wiki.resalliance.org

2) E.g. http://knb.ecoinformatics.org/knb/metacat/nceas.929.6/nceas [Includes metrics of avian community structure and human incidence of West Nile Virus, eastern U.S, accessed 2008-06-30]

\section{Ecology on the Internet}

An example of the ability of informal ICT-information to support ecological monitoring, was the use of email list servers to disseminate and compile field observations tracking coral bleaching on a global scale during the 1997-1998 El Niño event. The existence of an e-mail based coral listserver, proved fundamental for prompt assessments of the global mass bleaching event (Hoegh-Guldberg 1999), with reports ranging from "detailed accounts with accurate measures of bleaching and mortality, to brief anecdotal reports obtained during a rapid site visit" (Wilkinson 1999; see Box 1). Information of this kind can in principle easily be associated with participatory 
ecological monitoring projects, or citizen science initiatives, provided that they are posted on the Internet (see e.g. Andrianandrasana et al. 2005 on wetland monitoring in Madagascar; Leach and Scoones 2006 on participatory GIS "citizen- maps" for hydrological monitoring).

\section{[Box 1. Mail excerpts from Coral List 1998]}

One main challenge however, lies in designing monitoring systems that are able to scan the Internet continuously for predefined ecological events and changes that might signal emerging ecological vulnerabilities; and integrate that information with existing official monitoring data. While we are far away from such a fully operative system, innovative uses of web crawlers (software programs or automated scripts that browse the World Wide Web in a methodical, automated manner) are likely to provide an important complement to conventional monitoring. The case of the live reef fish trade seems to be a clear example of the difficulties in relying on official data alone, where innovative uses of unofficial data could provide a much needed complement (see Box 2).

\section{[Fig 1. Chinese screen shot]}

The potential of web crawlers is illustrated by the success of the Global Public Health Intelligence Network (GPHIN), an early detection system developed for the World Health Organization (WHO) by Health Canada. GPHIN gathers information of unusual disease events by monitoring Internet-based global media sources such as news wires, web sites, local online newspapers, and public health e-mail information services in eight languages. Non-English articles are filtered through a translation engine, and the system retrieves approximately 2,000 to 3,000 news items per day. Roughly $30 \%$ are rejected as duplicative or irrelevant, but the remaining items are sorted by GPHIN analysts and posted on GPHIN's secure website for use (Weir and Mykhalovskiy 2006).

The ability to trawl extensively for various signals, the wide diversity of information sources, and the capacity to identify alarming behaviors seems to give the system the flexibility and speed needed to detect surprising disease outbreaks. For example, GPHIN currently picks up the first hints of about $40 \%$ of the $200-250$ outbreaks subsequently investigated and verified by WHO each year. GPHIN was also one of the systems able to first pick up non-official reports of a suspected influenza outbreak in mainland China in 2002, three months later to be confirmed by the WHO as SARS (Severe Acute Respiratory Syndrome) in a global alert (Fidler 2005, Weir and Mykhalovskiy 2006).

\section{Web crawlers and Ecosystems}

Abrupt losses of ecosystem services are obviously difficult to forecast with certainty, especially since they result from multiple changes at different scales (Clark et al. 2001). Research on coupled social and ecological systems in the last decade have, however, identified a number of changes which may give early warnings of potentially destructive and surprising losses of ecosystem services. For example, an abrupt transition from a coral-dominated to an algaedominated coral reef may be preceded by declining abundance of large herbivorous fish (Nyström et al. 2000); a rapid transition from a clear to a highly turbid and eutrophic state in lakes may be preceded by increased fertilizer use among nearby farmers (Gordon et al. 2008); and heavy investment in specific fishing gear and technical equipment may precede the loss of certain key species in marine fisheries (Berkes et al. 2006). Figure 3 uses the example from coral reef ecosystems to illustrate diverse sources of Internet-based information on both drivers as well as ecosystem responses, to monitor and forewarn of pending ecological shifts. The 
collection and presentation of signals nonetheless needs to be complemented with expert analysis, knowledge management approaches (e.g. McDermott 1999 for an elaboration), as well as with local ecological and social understandings in order to provide robust estimates of possible effects, and success of countermeasures or adaptation strategies (cf. Crowl et al. 2008).

\section{[Figure 2. Using Internet based data as a complement]}

Analysis and response are not necessarily organized around a single (government) actor. On the contrary, both might take place as the result of collaborations including state agencies, and other expert analysts in the form of non-governmental organizations, private companies, universities and civil society in general. If the outputs are available more widely, analysis and responses could even be the result of autonomous actions, assumed by independent organizations and individuals.

\section{Avoiding Late Warnings}

There are important differences between monitoring for loss of ES and disease outbreaks. Web crawler based early warning systems for epidemics rely on the identification of discrete events (Weir and Mykhalovskiy 2006), rather than monitoring of underlying social, economic or ecological changes. However, discrete events can in principle be used as "early warnings" of approaching abrupt shifts in ecological systems. Given the potential for irreversible loss of ES, early warnings are important to allow management responses before the loss of ES. Here we suggest three potential approaches in using web crawlers to forewarn of ecological shifts.

Firstly, web crawlers can collect information on the drivers of ecosystem change, rather than the resultant ecological responses. For example, if rapidly emerging markets for high value species are known to be socio-economic drivers which lead to overexploitation and collapse of a fishery (see Box 2), web crawlers can be designed to collect information on rapid changes in prices, landings or investments in particular regions (e.g. Figure 1). Meyerson and Reaser (2003), for example, report on a web crawler developed by the US Department of Agriculture's Animal and Plant Health Inspection Service, to search and report sales of prohibited organisms over the Internet in their attempts to address the threat of invasive alien species.

\section{[Box 2. Web crawlers and Live Fish Trade]}

Secondly, future early warning systems can make use of the recent insight that variance within ecosystems can increase in response to stress. The variability of fish populations has for example been shown to increase in response to exploitation (Hsieh et al. 2006). Carpenter and Brock (2006) argue that variance within complex ecological systems generally increases in advance of catastrophic shifts. Although web crawlers harvest information on discrete events rather than the time-series needed to formally analyze variance patterns, increases in variance is very likely to result in increased frequency of what is perceived as "unusual events", hence making its way into e.g. local newspapers, blogs or communication in mail-lists (Figure 3A). It should nonetheless be noted that the argument that increased variance indicates a pending ecological shift is recent, and based on ecological modeling (cf. van Nes and Scheffer 2007; Oborny et al. 2005). Whether this second approach is possible to associate with web crawler based monitoring systems hence needs to be explored further.

[Figure 3A and 3B] 
Thirdly, a more clear-cut approach, builds on the fact that a web crawler may find information which describes ecological shifts at small scales, which may forewarn of similar shifts in other locations or, more seriously, larger-scale systemic changes as small-scale ecological shifts 'cascade up' to larger spatial scales. Examples include outbreaks of invasive alien species (Meyerson and Reaser 2003), or the way in which resilience of ecosystems such as forest reserves and coral reefs, is thought to be dependent on surrounding refuge areas, which can help the recovery from small scale shifts through for example the movement of 'mobile link' species and supply of larvae (Nyström et al. 2000; Bengtsson et al. 2003; see Figure 3B). Hence, repeated small scale shifts may not only lead to a cumulative loss of 'spatial resilience', but also provide early indications of large scale systemic loss of ES (Figure 3B).

\section{Remaining Key Challenges: Data Management and Lack of Societal Response}

Despite the exciting possibilities of web crawlers for ecological monitoring and early warning, we recognize that crucial challenges need to be addressed before web crawler-based early warning systems can contribute to the avoidance of abrupt ecosystem change. There is still a need to integrate, verify and manage ecological and socio-economic data. Data integration, expert analysis and knowledge management has proven to be a major challenge for ecological monitoring (Carpenter et al. 2006), even for well-defined monitoring systems in developed countries. Communicable disease surveillance in the European Union (Amato-Gauci and Ammon 2008), and invasive species monitoring in the United States (Meyerson and Reaser 2003; Crowl et al. 2008) for example illustrate the challenges posed by fragmented and insufficient social and ecological data, and the continuous risk of creating "information junkyards" (McDermott 1999) instead of robust ecological monitoring systems. Any web crawler based monitoring system as proposed here would need a coupled knowledge management and expert judgment system.

It should also be noted that early warnings are never a guarantee for early and appropriate remedial responses. The need for prompt responses to outbreaks of Ebola hemorrhagic fever and Avian influenza (H5N1) for example, have gained increased social and political support the last years, and spurred the development of new international regulations and response operations. This is facilitated by a relatively strong international organization for human health with an international mandate - the World Health Organization (Fidler 2005). This development stands in strong contrast with global environmental governance known to suffer from implementation deficits, serious coordination failures, and poor budgets (Biermann 2002). Responses to infectious disease (e.g. isolation, vaccination, medical care) are also likely to be simpler and less politically contentious, than responses to approaching ecological shifts (e.g. fishing restrictions, restrictions on agricultural activity, implementation of deforestation legislation).

The difficulties of data integration, and repeated non-response to ecological change does not, however, preclude the need for policy-makers and ecologists to explore innovative solutions to bridge the increasing gap between fragmented monitoring systems, and the rapid rate of social-ecological change with potentially serious repercussions for human well-being. Web crawlers should be explored further in attempts to prepare for the vast ecological challenges of an uncertain future. 


\section{References}

Amato-Gauci, A. and A. Ammon. 2008. The Surveillance of Communicable Diseases in the European Union - A Long-Term Strategy. Eurosurveillance 13:26.

Andrianandrasana, H.T., J. Randriamahefasoa, J. Durbin et al. 2005. Participatory Ecological Monitoring of the Alaotra Wetlands in Madagascar. Biodiversity and Conservation 14: 27572774.

Bengtsson, J., P. Angelstam, T. Elmqvist et al. 2003. Reserves, Resilience and Dynamic Landscapes. Ambio 32: 389-396.

Berkes, F., T. P. Hughes, R. S. Steneck, et al. 2006. Globalization, roving bandits, and marine resources. Science 311:1557-1558.

Biermann, F. 2002. Green global governance - The case for a World Environment Organisation. New Economy 9: 82-86.

Carpenter, S.R., R. DeFries, T. Dietz et al. 2006. Millennium Ecosystem Assessment: Research Needs. Science 314: 257-258.

Carpenter, S.R. and W. A. Brock. 2006. Rising variance: a leading indicator of ecological transition. Ecology Letters 9: 311-318.

Clark, J.S., S.R. Carpenter, M. Barber et al. 2001. Ecological Forecasts: An Emerging Imperative. Science 293: 657-660.

Crowl, T.A., T.O. Crist, R.R. Parmenter et al. 2008. The spread of invasive species and infectious disease as drivers of ecosystem change. Frontiers in Ecology and the Environment 6: 238-246.

Danielsen F., M.M. Mendoza, P. Alviola et al. 2003. Biodiversity monitoring in developing countries: what are we trying to achieve? Oryx 37: 407-409.

Fidler D.P. 2005. SARS, Governance and the Globalization of Disease. Palgrave McMillan, New York.

Gordon, L., G. D. Peterson and E.M. Bennett. 2008. Agricultural modifications of hydrological flows create ecological surprises. Trends in Ecology and Evolution 23: 211-219.

Gunderson, L.H. 2003. Adaptive Dancing: Interactions Between Social Resilience and Ecological Crises. in Navigating Social-ecological systems: Building resilience for complexity and change, F. Berkes J. Colding C. Folke , Eds., Cambridge University Press, Cambridge: 3352.

Hsieh, C. H., C. S. Reiss, et al. 2006. Fishing elevates variability in the abundance of exploited species. Nature 443(7113): 859-862. 
Hoegh-Guldberg, O. 1999. Climate change, coral bleaching and the future of the world's coral reefs. Mar. Freshwater Res. 50: 839-866.

IER. 2005. Information Economy Report. United Nations Conference on Trade and Development. United Nations, New York and Geneva.

Leach, M. and I. Scoones. 2006. The Slow Race: Making Technology Work for the Poor. Demos. London, United Kingdom.

Levitt, J.N. ed. 2002. Conservation in the Internet Age: Threats and Opportunities. Island Press. Washington D.C.

McCook LJ, Folke C, Hughes TP, et al. 2007. Chapter 4 - Ecological resilience, climate change and the Great Barrier Reef. In: Johnson JE, Marshall PA (eds) Climate change and the Great Barrier Reef. Great Barrier Reef Marine Park Authority and Australian Greenhouse Office, Australia.

McDermott, R. 1999. Why Information Technology Inspired But Cannot Deliver Knowledge Management. In Lesser, E.L., MA. Fontaine, JA. Slusher (Eds). Knowledge and Communities. Butterworth-Heinemann, Boston: 21- 36.

Meyerson L.A. and J.K. Reaser. 2003. Bioinvasions, Bioterrorism, and Biosecurity. Frontiers in Ecology and the Environment 1: 307-314.

Millennium Ecosystem Assessment. 2005. Ecosystems and Human Well-Being. Island Press.

Nyström, M., C. Folke, F. Moberg. 2000. Coral reef disturbance and resilience in a humandominated environment. Trends in Ecology and Evolution 15: 413- 417.

Nyström M., NAJ Graham , J. Lokrantz , A. Norström. In press. Capturing the cornerstones of coral reef resilience: linking theory to practice. Coral Reefs.

Oborny, B., G. Meszéna, G. Szabó. 2005. Dynamics of populations on the verge of extinction. Oikos, 109: 291-296.

Sadovy, Y.J., T.J. Donaldson, T.R. Graham, et al. 2003. While Stocks Last: The Live Reef Food Fish Trade. Asian Development Bank, Manila. 169 pp.

Scales, H. Balmford, A. Liu, et al. 2006. Keeping Bandits at Bay? Science 313: 612-613.

Scheffer, M., S.R. Carpenter, J.A. Foley et al. 2001. Catastrophic Shifts in Ecosystems. Nature 413: 591-596.

Schneider, S.H. and T.L. Root. 1995. Ecological implications of climate change will include surprises. Biodiversity and Conservation 5: 1109-1119.

UNEP. 2007. Global Environment Outlook - GEO4. United Nations Environment Programme, Nairobi. 
van Nes, E. and M. Scheffer. 2007. Slow Recovery from Perturbations as a Generic Indicator of a Nearby Catastrophic Shift. American Naturalist 169: 738-747.

Walters, C.J. 2007. Is Adaptive Management Helping to Solve Fisheries Problems? Ambio 36: 304-307.

Weir, L. and E. Mykhalovskiy. 2006."The Geopolitics of Global Public Health Surveillance in the Twenty-First Century. In A. Bashford (ed). Medicine at the Border - Disease, Globalization and Security, 1850 to the Present. Palgrave McMillan: 240-263.

Wilkinson, C. R. 1999. The 1997-1998 mass bleaching event around the world. Compilation of Internet Reports, Global Coral Reef Monitoring Network, Australian Institute of Marine Science special publication. 
Figure 1. Ecological information is often accessible in a number of languages, and diverse settings on the Internet. This "screen shot" from a Chinese food market webpage, illustrates the type of information that can be retrieved. Marked section 1. Information about marine species on the market for sale, with information about observed highest, lowest and average price. Last column provides price statistics for the chosen species. Marked section 2. News section including changes in access to specific marine species. First news item reads: "According to an integrated investigation of the coastal zone, both Chinese prawn and little yellow croaker have returned in the Bohai Sea." Sixth news item: "Big stocks of little yellow croaker have re-emerged after 30 years in the Yellow Sea". Translation and web search assisted by Guoyi Hahn, Stockholm Environment Institute.

Online source:

http://www.21food.cn/news/price.jsp?category=\%CB\%AE\%B2\%FA\%C6\%B7\&product=\%D0\%A1\%BB\%C 6\%D3\%E3\&Submit2=\%BF\%AA\%CA\%BC\%B2\%E9\%D1\%AF [accessed 2008-06-26]. 


\section{Figure 2. Using informal Internet data as a complement to conventional monitoring}

Examples of drivers and impact signals that in principle can be detected by a web crawler for a coral reef social-ecological system. "Driver signals" are key social, ecological, and economic factors that risk leading to loss of ecosystem services. "Impact signals" indicate changes that may signal pending loss of ecosystem services. Note that the list of signals is not exhaustive. Based on (Nyström et al. 2000; Berkes et al. 2006; Scales et al. 2006; McCook et al. 2007). The analysis of these signals is not necessarily made by one single actor, but could rather include a set of expert analysts ranging from e.g. academia, United Nations agencies, non-governmental organizations, civic scientists to military and diplomatic agencies. Illustration by B. Crona and R. Kautsky/Azote. 
Fig 3A. Discrete events as early warnings

Increasing variance of a key system variable (e.g. fish abundance or nutrient concentration) over time (above). As variance increases, the probability distribution changes so that extreme values beyond a certain threshold (dotted lines) become more likely and frequent. Such increasing variance can therefore give rise to more frequent observations of (what used to be) "unusual" events that may be reported in online sources.

\section{Figure 3B. Discrete events as early warnings of loss of spatial resilience}

Ecological shifts at a small scale can be warnings of impending large-scale system shifts. Shifts at a large scale may be difficult to reverse due to a new stable state while a high proportion of healthy reefs confers spatial resilience on the whole system. System a) has a high spatial resilience. Recovery from any disturbance is assisted by multiple sources of 'ecological memory' making large-scale shifts unlikely. b) Higher frequency of local shifts, in turn decreasing the recovery of individual local systems and increasing the risk of moving to (c). c) Large-scale phase shift. The majority of sites are degraded making recovery of the local sites and the large-scale system unlikely. Adopted from Nyström et al., in press. 


\section{Box 1. Example excerpts from Coral List from early 1998.}

Accessible from http://www.coral.noaa.gov/lists/archives.shtml (accessed on 27.6.08).

Senders e-mail addresses have been removed, and region added by article authors.

\section{Panama}

Wed, 1 Oct 1997 14:49:26 -0500

Significant coral bleaching was observed on 17 September 1997 at Uva Island

in the Gulf of Chiriqui, Pacific Panama. All zooxanthellate scleractinian

coral species were affected, at all depths (no corals present $>20 \mathrm{~m}$ ). The

most severely bleached (completely white) colonies still had extended

polyps and no signs of algal overgrowth, suggesting the event occurred

relatively recently. Most colonies of the hydrocoral Millepora intricata

(the only common species of the genus remaining after the 1982-83 ENSO)

were already dead and covered with a thin algal film, suggesting they may

have bleached earlier than the scleractinians.

\section{Galapagos}

Thu Jan 5 21:11:06 1998 
As of Dec. $18-30$ bleaching was observed first hand in Galapagos. Roughly $20 \%$ of polyps of roughly $80 \%$ of the coral I saw was bleached near the top (mostly a brown lumpy coral, I don't know the name, anyone?) although I was only able to visit Santa Cruz, Bartolome, Santa Fe, and Espanola; NOT the islands typically known for large coral assembleges (Devil's Crown, Isabella).

Hope this helps.

\section{Galapagos}

Sat Jan 21 12:32:09 1998

FYI, a NOAA Press Release:

EL NINO CAUSING CORAL BLEACHING IN GALAPAGOS,

NOAA ANNOUNCES EI Niño's extremely warm waters in the Pacific Ocean have caused coral bleaching in the waters around the Galapagos Islands, the Commerce Department's National Oceanic and Atmospheric Administration announced today.

\section{Hawaii}

Date: Tue, 3 Mar 1998 20:46:37 -1000

Subject: Gidday Mate !

$>$ The coral reef here is a bloody disaster. What isn't dead is bleached

so white from loss of algae that I think much of it will starve before it 
comes good. The sea temp reached $33 \mathrm{c}$ at 15 meters depth at four mile reef last month. We are getting South easters now bringing in cooler water but it is still very hot. This is unprecedented. No one can remember anything like this happening before.

\section{Western Samoa}

Date: Thu, 5 Mar 1998 13:20:18 -1100

A survey at Palolo Deep (a National MarinePark near Apia, Western Samoa)

on 28 February revealed severe coral bleaching. Between 60 to $70 \%$ of all staghorn Acopora on the reef top was bleached. This has occurred with amazing rapidity (over a period of 5-6 days). In deeper water, all seemed well. 


\section{Box 2. Web crawlers and Live Fish Trade}

Globalised markets have become important drivers for fisheries systems, driving rapid development, overexploitation and collapse of local fisheries, before effective management can be established (Berkes et al. 2006). The live reef fish trade (LRFT) supplying seafood to restaurants in Asia is a good example. This fishery has been characterized by a boom-and bust pattern of sequential exploitation of reefs and nations, and serial depletion of the most valuable species (Scales et al. 2006). While some Pacific Ocean nations have recognized the threat of LRFT and have started to take precautionary actions, coordinated by the Secretariat of the Pacific Community (Sadovy et al. 2003), many in other areas, such as the Caribbean and the Western Indian Ocean, have not, and data availability on the status of many small-scale reef fisheries has also been a severe impediment to action. Socio-economic and ecological signals provided by web crawlers, could potentially improve early detection of nations and regions at risk of being hit by the next sequential wave of LRFT. Examples of the types of signals that could be used include trade adverts, availability of products by area, prices, number of suppliers, observations by non-state actors such as environmental organizations, and newsletters. 


\section{Acknowledgements}

This work was supported by the Stockholm Resilience Centre, and by grants from the Foundation for Strategic Environmental Research (Mistra). We thank Frances Westley

(University of Waterloo), and a number of colleagues for initial inspirational discussions, and three anonymous reviewers for comments on earlier drafts of the article. 
Drivers of system change

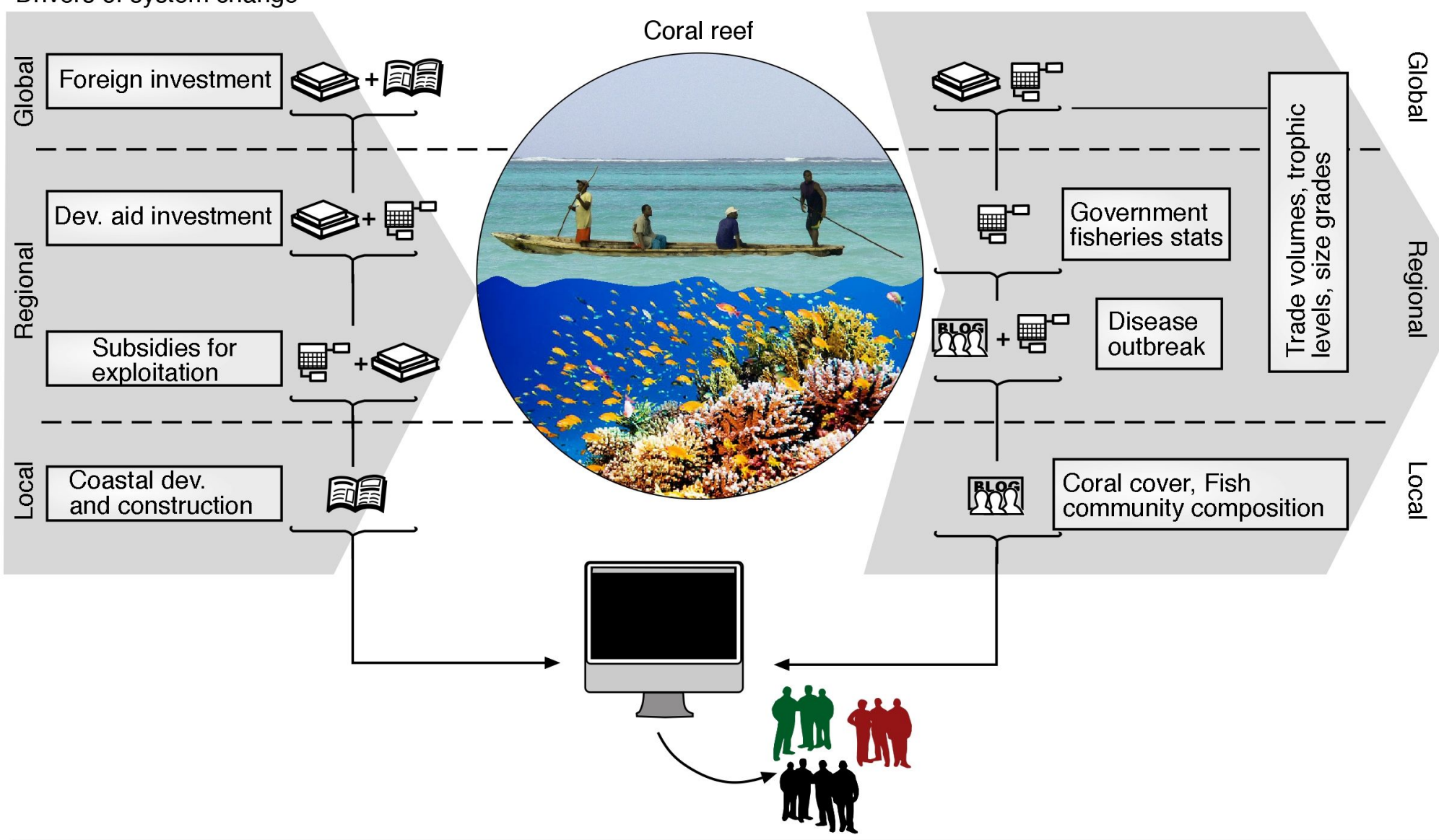

Online news media. E.g. newspapers, radio, and television and online newsletters.

网 Blogs. E.g. dialogues conducted through dive clubs, interests groups, NGOs, listserves, purchase requests.
Published (online) reports and documents from government agencies, UN agencies, OECD, and similar

Online accessible databases. E.g. trade statistics, landing statistics. 
Time series

Distributions
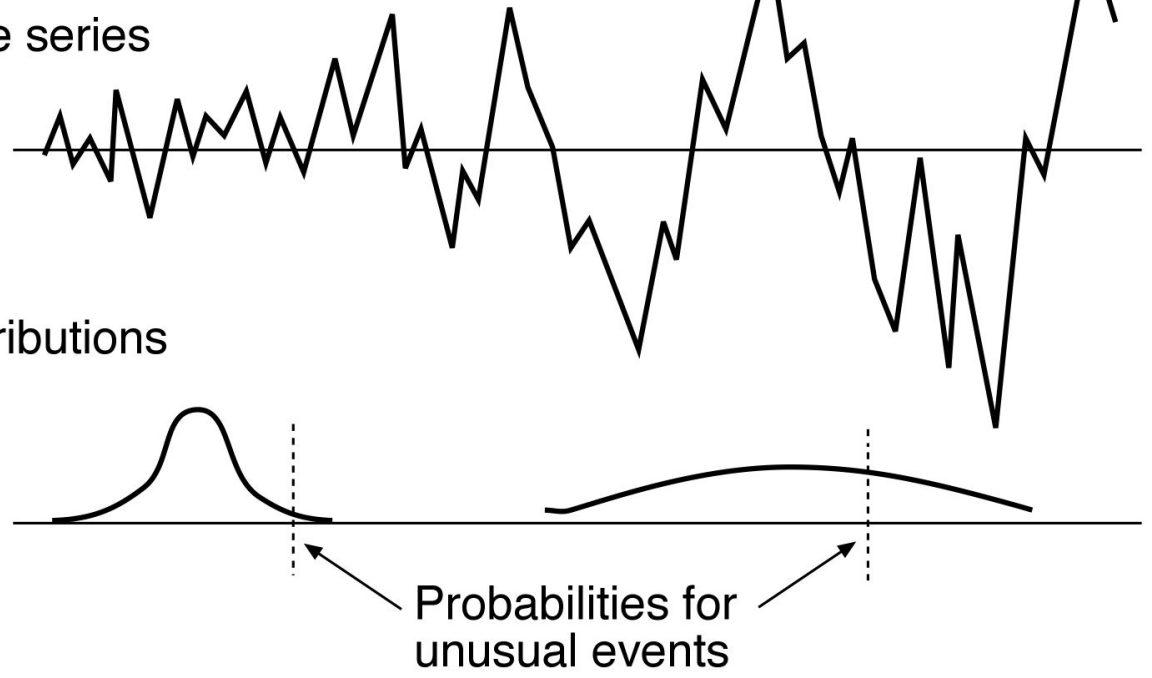
(a)

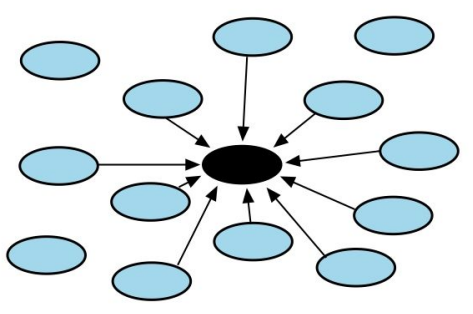

(b)

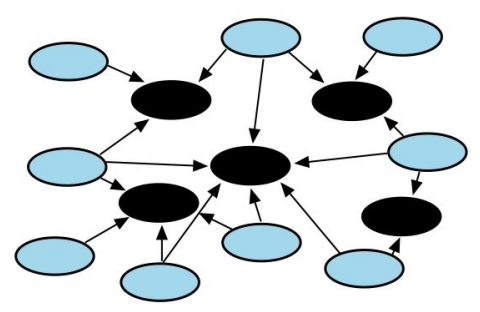

(c)

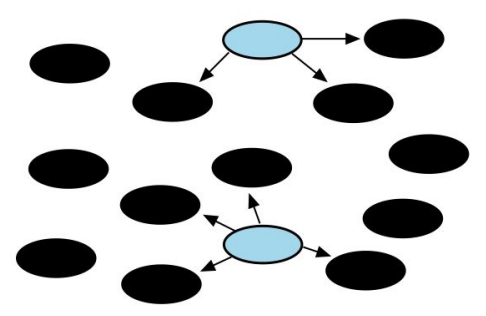

$\bigcirc$ Healthy local ecosystem

Local ecosystem in degraded state

$\longrightarrow$ Flows from refuge areas to assist recovery 